\title{
Comparative Study of Tritium Analysis Method with High-Volume Counting Vial
}

\author{
Yoon Yeol Yoon, Yongcheol Kim \\ Geologic Environment Division, Korea Institute of Geoscience and Mineral Resources, Daejeon, Korea
}

\section{Technical Paper}

Received May 12, 2020

Revision June 15, 2020

Accepted July 15, 2020

Corresponding author: Yoon Yeol Yoon

Division of Geologic Environment, Korea Institute of Geoscience and Mineral Resources, 124 Gwahak-ro, Yuseong-gu, Daejeon 34132, Korea

E-mail:yyyoon@kigam.re.kr

(D) https://orcid.org/0000-0002-6706-2455

This is an open-access article distributed under the terms of the Creative Commons Attribution License (http://creativecommons.org/licenses/by-nc/4.0), which permits unrestricted use, distribution, and reproduction in any medium, provided the original work is properly cited.

Copyright $\odot 2020$ The Korean Association for Radiation Protection

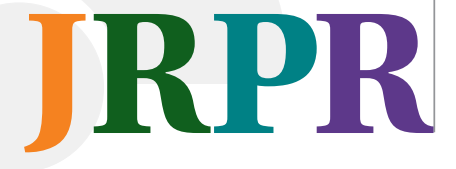

Background: Tritium $\left({ }^{3} \mathrm{H}\right)$ analysis in groundwater was difficult because of its low activity. Therefore, the electrolytic enrichment method was used. To improve the detection limit and for performing simple analysis, a high-volume counting vial with the available liquid scintillation counter (LSC) was investigated. Further, it was compared with a conventional $20-\mathrm{mL}$ counting vial.

Materials and Methods: The LSC with the electrolytic enrichment method was used ${ }^{3} \mathrm{H}$ analysis in groundwater. A high-volume 145 -mL counting vial was compared with a conventional 20-mL counting vial to determine the counting characteristics of different LSCs.

Results and Discussion: When a Quantulus LSC was used, the counting window between channels 35 and 250 was used. The background count was approximately $1.86 \mathrm{cpm}$, and the counting efficiency increased from $8 \%$ to $40 \%$ depending on the mixing ratio of the volume of sample and cocktail solution. For LSC-LB7, the optimum counting window was between 1 and $4.9 \mathrm{keV}$, which was selected by the factory (Hitachi Aloka Medical Ltd., Japan) by considering quenching using a standard external gamma source. The background count of LSC-LB7 was approximately $3.60 \pm 0.29 \mathrm{cpm}$ when the $145-\mathrm{mL}$ vial was used and $2.22 \pm 0.17 \mathrm{cpm}$ when the 20 -mL vial was used. The minimum detectable activity (MDA) of the 20 -mL vial was greater for LSC-LB7 than for Quantulus. The MDA with the $145-\mathrm{mL}$ vial was improved to $0.3 \mathrm{~Bq} / \mathrm{L}$ when compared with the value of $1.6 \mathrm{~Bq} / \mathrm{L}$ for the $20-\mathrm{mL}$ vial.

Conclusion: The counting efficiency when using the $145-\mathrm{mL}$ vial was $27 \%$, whereas it was $18 \%$ when using the $20-\mathrm{mL}$ vial. This difference can be attributed to the vial volume. The figure of merit (FOM) of the $145-\mathrm{mL}$ vial was four times greater than that of the $20-\mathrm{mL}$ vial because the volume of the former vial is approximately seven times greater than that of the latter. Further, the MDA for ${ }^{3} \mathrm{H}$ decreased from 1.6 to $0.3 \mathrm{~Bq} / \mathrm{L}$. The counting efficiency and FOM of LSC-LB7 was slightly less than those of Quantulus when the $20-\mathrm{mL}$ vial was used. The background counting rate of the Quantulus was lower than that of the LSC-LB7.

Keywords: LSC-LB7, High Volume Vial, Tritium

\section{Introduction}

Tritium $\left({ }^{3} \mathrm{H}\right)$ is the radioactive hydrogen isotope with pure beta emitter $\left(\mathrm{E}_{\max }=18.6\right.$ $\mathrm{keV}$ ) and have a half-life of $4,500 \pm 8$ days [1]. This radionuclide is naturally produced in the environment by cosmic-ray bombardment of nitrogen and deuterium in the upper atmosphere and also some of them is produced artificially by nuclear power plants. Produced tritium is reacted very quickly with hydrogen and oxygen and changed to water molecules. Tritium is generally encountered in various components of the hy- 
drosphere including atmosphere, rivers, marine waters, underground waters, interstitial water in soils and sediments. Therefore, it is widely used in the field of hydrogeology for its tracing properties enabling to estimate water origin, residence time, dynamic, mixing, storage volumes of groundwater and their zone of discharge in surface waters [2-5].

Tritium concentration in water (HTO form) is often reported in tritium unit (TU) and 1 TU represents one HTO molecule in $10^{18} \mathrm{H}_{2} \mathrm{O}$ molecules and this means $0.1190 \pm 0.0002 \mathrm{~Bq} / \mathrm{kg}$ of water. Tritium activity measurement in environment is very difficult due to its very low concentration. Theoretical tritium production rate in atmosphere is about 0.5 atoms. $\mathrm{cm}^{-}$ ${ }^{2} \cdot \mathrm{s}^{-1}$ and the total amount of ${ }^{3} \mathrm{H}$ in the earth is about $3.6 \mathrm{~kg}$ [6]. The ${ }^{3} \mathrm{H}$ amount is $10-20 \mathrm{TU}$ at the northern hemisphere and below $10 \mathrm{TU}$ at the southern hemisphere $[7,8]$. Therefore this low activity are difficult to analyze directly. To overcome this difficulty, most of the water samples were enriched using electrolytic enrichment method [9, 10]. Liquid scintillation counter (LSC) is mostly used instrument for ${ }^{3} \mathrm{H}$ analysis and most of the LSC used $20 \mathrm{~mL}$ vial.

In this study, we used $145 \mathrm{~mL}$ vial available LSC for analyzing natural level tritium and electrolytic enrichment method was also applied for extremely low activity tritium measurement. And ${ }^{3} \mathrm{H}$ analysis was compared with two kinds of LSC and counting vials.

\section{Materials and Methods}

Tritium was analyzed with two kinds of LSC, one is Quantulus 1220 (PerkinElmer Inc., Waltham, MA, USA) and the other is AccuFLEX LSC-LB7 (Hitachi, Tokyo, Japan), and counting performance was compared with $20 \mathrm{~mL}$ and $145 \mathrm{~mL}$ Teflon lined polypropylene vial. These two instrument used guard counter for reducing the effects of external radiation, anti-coincidence signal detection and massive layer of lead but LSC-LB7 has been realized by the unique detector structure for counting with the vial up to $145 \mathrm{~mL}$ as well as $20 \mathrm{~mL}$ [11-13].

For ${ }^{3} \mathrm{H}$ analysis, about $1 \mathrm{~L}$ groundwater samples are distilled and electrolytic enrichment process was performed as previous work [10]. For the comparison of different counting vials, $500 \mathrm{~mL}$ groundwater was used for $20 \mathrm{~mL}$ counting vial and $1 \mathrm{~L}$ sample was used for $145 \mathrm{~mL}$ counting vial.

For comparison of detection efficiency and figure of merit (FOM), $1 \mathrm{~mL}$ of diluted ${ }^{3} \mathrm{H}$ standard solution ( ${ }^{3} \mathrm{H}$ activity, 60 Bq/g; SRM 4926E) was added to the each $20 \mathrm{~mL}$ and $145 \mathrm{~mL}$ counting vial and distilled water, which was old groundwater, was mixed with liquid scintillation cocktail solution (Ultima Gold LLT; PerkinElmer Inc.) with different volume ratio. All prepared samples were counted after 1 day for eliminating luminescence effect. FOM of each vials were compared with water and cocktail mixing ratio and MDA (minimum detectable activity) was also calculated by counting old groundwater.

Tritium counting efficiency was estimated using the National Institute of Standards and Technology (NIST) standard water sample (SRM 4926E, water). After counting condition was compared, some groundwater samples were analyzed with two kinds of LSC and vials and compared analytical result.

\section{Results and Discussion}

Direct environment ${ }^{3} \mathrm{H}$ counting is impossible by LSC counting. Because current environmental ${ }^{3} \mathrm{H}$ concentration is below 20 TU. Most available direct ${ }^{3} \mathrm{H}$ content by LSC was more than $40 \mathrm{TU}$, therefore electrolytic enrichment method was used. For the detection of low content of ${ }^{3} \mathrm{H}, 145 \mathrm{~mL}$ counting vial available LSC was used and compared with conventional $20 \mathrm{~mL}$ counting vial. The counting efficiency and FOM with water and cocktail mixing ratio was shown in Fig. 1. FOM was calculated as following Equation (1). This value was varied from 1,300 to 14,000 depends on water and cocktail mixing ratio in case of $20 \mathrm{~mL}$ vial. But this value of $145 \mathrm{~mL}$ vial when counted by LSC-LB7 was ranged from 27,000 to 450,000 .

$$
\mathrm{FOM}=\frac{(E \cdot V)^{2}}{B}
$$

where, E is counting efficiency (\%), V is sample volume $(\mathrm{mL})$, and B is background (cpm). When Quantulus LSC was used, counting window was used between 35 to 250 channels. The background count was about $1.86 \mathrm{cpm}$ and counting efficiency was changed from $8 \%$ to $40 \%$ with mixing ratio. In case of LSC-LB7, optimum counting window was set between 1 and $4.9 \mathrm{keV}$, which window was selected by factory considering quenching by using standard external gamma source. The background of LSC-LB7 was about $3.60 \pm 0.29 \mathrm{cpm}$ and $2.22 \pm 0.17 \mathrm{cpm}$ when $145 \mathrm{~mL}$ and $20 \mathrm{~mL}$ vial was used. Counting efficiency was changed from $10 \%$ to $32 \%$ with different water cocktail mixing ratios. Optimum counting condition was acquired from FOM data, and $10 \mathrm{~mL}: 10 \mathrm{~mL}$ water 

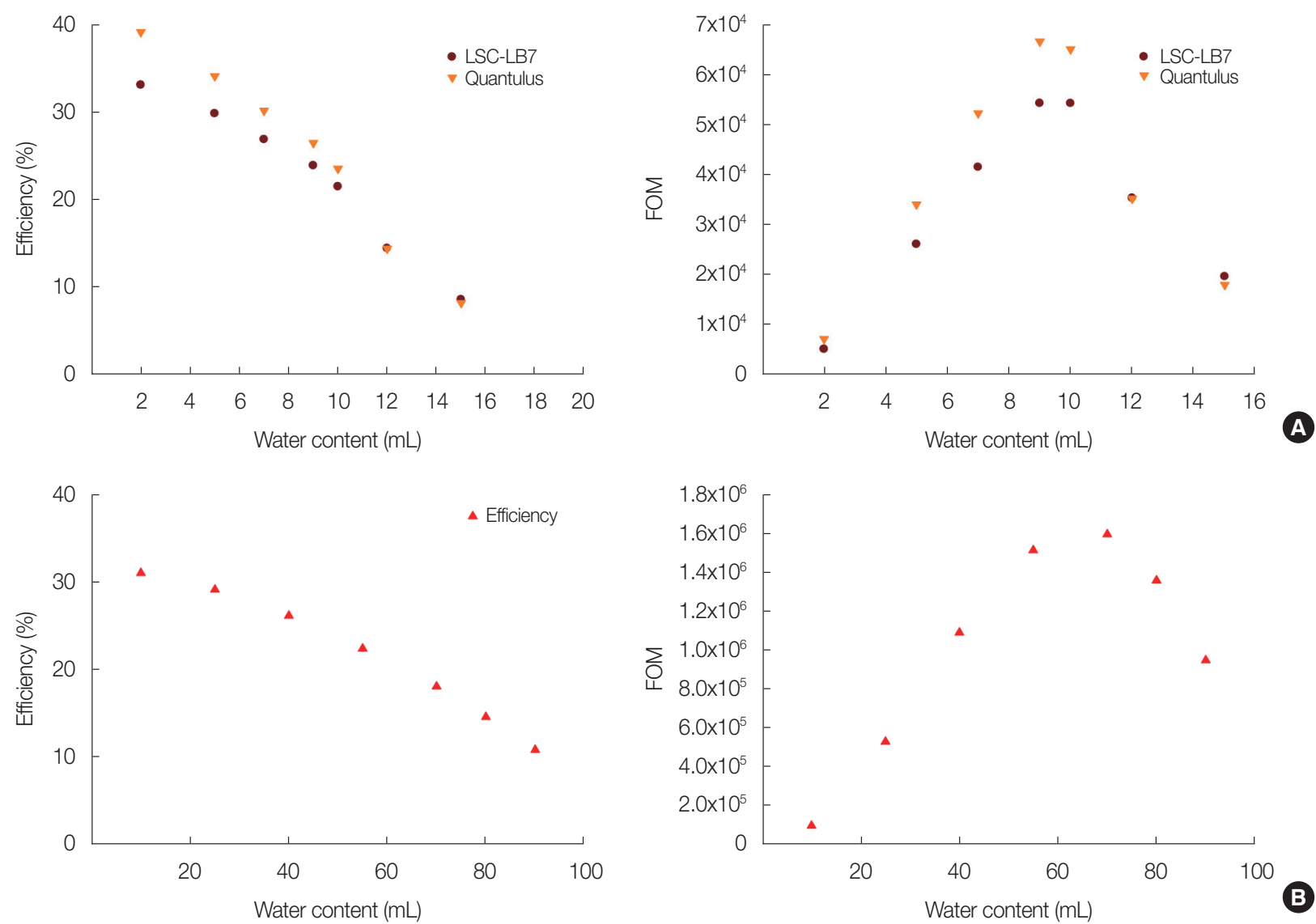

Fig. 1. Counting efficiency and figure of merit (FOM) comparison with different counting vials: (A) $20 \mathrm{~mL}$ vial and (B) $145 \mathrm{~mL}$ vial.
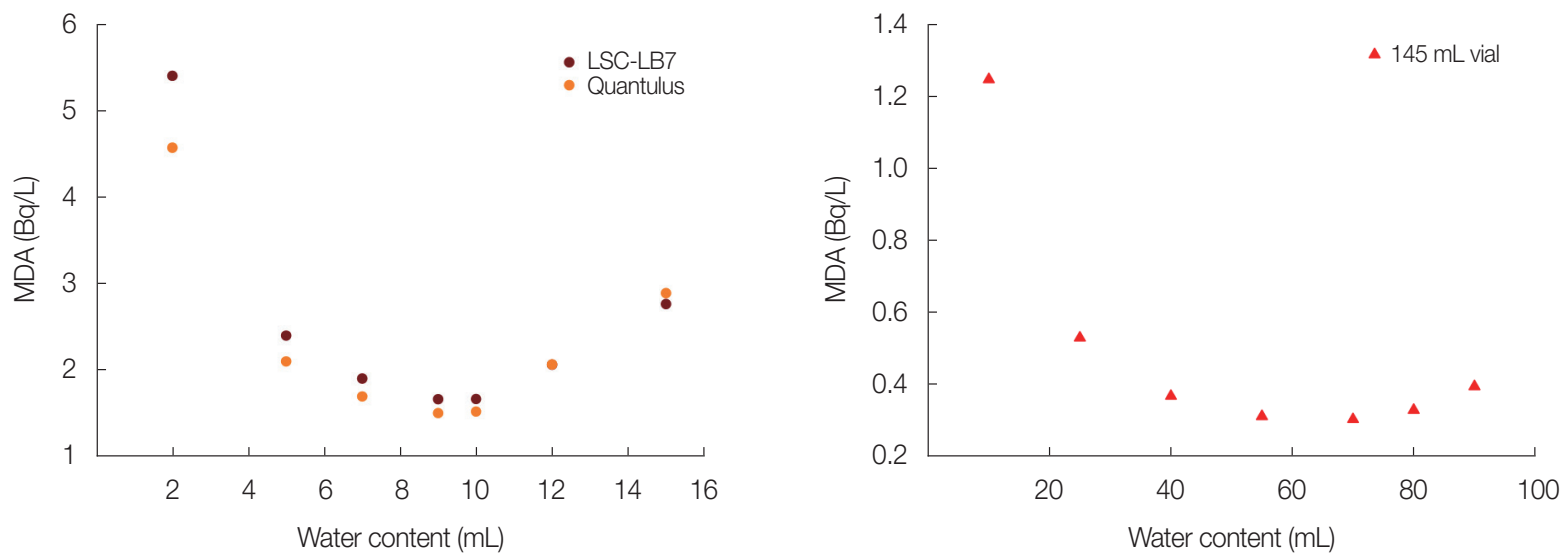

Fig. 2. Detection limit comparison with different counting vials (right) and liquid scintillation counter (left). MDA, minimum detectable activity.

and cocktail ratio was optimum when $20 \mathrm{~mL}$ vial was used. And also, $70 \mathrm{~mL}: 70 \mathrm{~mL}$ water and cocktail ratio was optimum when $145 \mathrm{~mL}$ vial was used. But some overflow was occurred when $145 \mathrm{~mL}$ vial was used, therefore, $66 \mathrm{~mL}$ cocktail was used for sample analysis. Counting efficiency of $20 \mathrm{~mL}$ vial was little bit low in case of LSC-LB7. This LSC have three phototubes, so distance between sample and phototube was lon- ger than two phototube LSC. Therefore, counting efficiency was low due to geometrically long distance. And also low efficiency was acquired in case of $145 \mathrm{~mL}$ vial. This result was occurred because all emitting light was not detected due to big size of vial rather than phototube.

Detection limit of two different LSC and vials was compared and the results were shown in Fig. 2. When the count- 
Table 1. Comparison Data of LB7 and Quantulus

\begin{tabular}{lcc}
\hline & LB7 & Quantulus \\
\hline Efficiency (\%) & $18.2 \pm 0.2$ & $28.7 \pm 0.3$ \\
Background (cpm) & $3.60 \pm 0.29$ & $1.86 \pm 0.23$ \\
MDA (Bq/L) & 0.3 & 1.6 \\
FOM & 450,000 & 44,000 \\
Enrichment time $^{\text {a) }}$ (day) & 8 & 10 \\
\hline
\end{tabular}

Values are presented as mean \pm standard deviation. MDA, minimum detectable activity; FOM, figure of merit.

a) Sample volume was $600 \mathrm{~mL}$.

ing time was 10 hours and $1 \mathrm{~L}$ sample was used, MDA value was calculated by Currie method [14]. MDA of $20 \mathrm{~mL}$ vial was high in case of LSC-LB7 rather than Quantulus due to high background count rate. But MDA was improved from 1.6 to $0.3 \mathrm{~Bq} / \mathrm{L}$ when $145 \mathrm{~mL}$ vial rather than $20 \mathrm{~mL}$ vial was used. Above comparison data of LB7 and Quantulus was presented in Table 1. Despite of the advantage of the performance of the LB7, some disadvantage was exist. One of them is high amount of the cocktail consumption and the other is low counting efficiency due to use high volume counting vial.

Some groundwater samples were simultaneously analyzed using $145 \mathrm{~mL}$ and $20 \mathrm{~mL}$ vial and the results were shown in Table 2. Groundwater samples were 10 times concentrated by electrolytic enrichment method and counted with two kinds of LSC. Some samples could be detected when $145 \mathrm{~mL}$ vial was used, whereas $20 \mathrm{~mL}$ vial was below detection limit. Therefore, detection limit is improved when $145 \mathrm{~mL}$ vial was used and it is more efficient using $145 \mathrm{~mL}$ vial when analyze low activity tritium.

\section{Conclusion}

For the analysis environmental ${ }^{3} \mathrm{H}$, high volume vial available liquid scintillation counter was used. And ${ }^{3} \mathrm{H}$ analysis was compared with conventional $20 \mathrm{~mL}$ counting vial. Counting efficiency of $145 \mathrm{~mL}$ vial was decreased from $27 \%$ in case of 20 $\mathrm{mL}$ vial to $18 \%$ due to big size vial but FOM was four times increased than $20 \mathrm{~mL}$ vial. And MDA of ${ }^{3} \mathrm{H}$ was improved from 1.6 to $0.3 \mathrm{~Bq} / \mathrm{L}$ due to seven times high sample volume. And also electrolytic enrichment time was decrease due to use high volume sample. FOM of LSC-LB7 was little bit low than Quantulus when $20 \mathrm{~mL}$ vial was used. Because LB7 had a high background and low counting efficiency rather than Quantulus, which was long distance between sample vial and detector due to high volume vial counting space.
Table 2. Tritium Analytical Results Comparison with Different LSC

\begin{tabular}{lccc}
\hline & \multicolumn{3}{c}{${ }^{3} \mathrm{H}(\mathrm{TU})$} \\
\cline { 2 - 4 } Sample & LSC-LB7 & Quantulus & LB7/Quantulus \\
\hline HS1-2 & $8.16 \pm 0.55$ & $7.48 \pm 0.65$ & 1.09 \\
HS2-2 & $3.90 \pm 0.28$ & $3.92 \pm 0.29$ & 1.00 \\
HS15-1 & $0.67 \pm 0.03$ & $<0.5$ & - \\
HS15-2 & $<0.3$ & $<0.5$ & - \\
MS-72 & $3.87 \pm 0.17$ & $3.43 \pm 0.27$ & 0.99 \\
MS-84 & $<0.3$ & $<0.5$ & - \\
MS-104 & $2.43 \pm 0.10$ & $1.99 \pm 0.14$ & 1.22 \\
MS-106 & $1.67 \pm 0.07$ & $1.74 \pm 0.16$ & 0.96 \\
\hline
\end{tabular}

Values are presented as mean \pm standard deviation.

LSC, liquid scintillation counter; TU, tritium unit.

\section{Conflict of Interest}

No potential conflict of interest relevant to this article was reported.

\section{Acknowledgements}

This research was supported by the Basic Research Project of the Korea Institute of Geoscience and Mineral Resources funded by the Ministry of Science and ICT (No. 20-3411).

\section{Author Contribution}

Formal analysis: Yoon YY. Funding acquisition: Kim Y. Methodology: Yoon YY. Project administration: Kim Y. Writing - review \& editing: Yoon YY. Supervision: Kim Y.

\section{References}

1. Firestone RB, Shirley VS. Table of isotopes. 8th ed. New York, NY: John Wiley \& Sons Inc.; 1996.

2. Gusyev MA, Morgenstern U, Stewart MK, Yamazaki Y, Kashiwaya $\mathrm{K}$, Nishihara T, et al. Application of tritium in precipitation and baseflow in Japan: a case study of groundwater transit times and storage in Hokkaido watersheds. Hydrol Earth Syst Sci. 2016;20: 3043-3058.

3. Mayer A, Sultenfuß J, Travi Y, Rebeix R, Purtschert R, Claude C, et al. A multi-tracer study of groundwater origin and transit-time in the aquifers of the Venice region (Italy). Appl Geochem. 2014; 50:177-198.

4. Subbotin SB, Aidarkhanov AO, Dubasov YV. Migration of tritium with underground waters on the former Semipalatinsk test site. Radiochemistry. 2013;55:557-565.

5. Ducros L, Eyrolle F, Vedova CD, Charmasson S, Leblanc M, Mayer 
A, et al. Tritium in river waters from French Mediterranean catchments: background levels and variability. Sci Total Environ. 2018; 612:672-682.

6. Cook P, Herczeg AL. Environmental tracers in subsurface hydrology. New York, NY: Springer; 2000.

7. Von Buttlar H, Libby WF. Natural distribution of cosmic-ray produced tritium. II. J Inorg Nucl Chem. 1955;1:75-91.

8. International Atomic Energy Agency. Guidebook on nuclear techniques in hydrology (1983 Edition). Vienna, Austria: International Atomic Energy Agency; 1983.

9. Taylor CB. Tritium enrichment of environmental waters by electrolysis: development of cathodes exhibiting high isotopic separation and precise measurement of tritium enrichment factors. Procedure and technique critique for tritium enrichment by electrolysis at the IAEA Laboratory; 1976 Nov 5; Seibersdorf, Austria.

10. Yoon Y, Lee K, Ko K. Development and validation of Ni-Ni elec- trolytic enrichment method for tritium determination in samples of underground waters of Jeju Island. J Radioanal Nucl Chem. 2010;286:591-595.

11. Tanaka R, Araki S, Mukai T, Yasuoka Y, Ohnuma S, Ishikawa T, et al. A simplified method for improved determination of radon concentration in environmental water samples. Radioisotopes (Tokyo). 2013;62:423-438.

12. Mullins S. A comparison of two liquid scintillation instruments for analysis of highly quenched samples. Proceedings of the Conference on Advances in Liquid Scintillation Spectrometry (LSC2017); 2017 May 1-5; Copenhagen, Denmark.

13. Feng B, Chen B, Zhuo W, Zhang W. A new passive sampler for collecting atmospheric tritiated water vapor. Atmos Environ. 2017;154:308-317.

14. Currie LA. Limits for qualitative detection and quantitative determination: application to radiochemistry. Anal Chem. 1968; 40:586-593. 